\title{
Corrigendum: A transactivation-deficient mouse model provides insight into p53 regulation and function
}

\section{G S Jimenez, M Nister, M Beeche, J S Stommel, E Barcarse, S O’Gorman \& G M Wahl \\ Nat. Genet. 26, 37-43 (2000).}

This article described the generation of a mouse in which homologous recombination was used to change codons 25 and 26 of the gene Trp53 to glutamine and serine. The initial sequencing of the full-length cDNA from mouse embryonic fibroblasts expressing this allele was considered to be wild-type at all codons except for 25 and 26. A reanalysis of the sequence showed that this mutant also contains a valine at codon 135, which is referred to as a "provisional wild type codon" in the National Center for Biotechnology Information's LocusLink tool (accession numbers: Trp53 mRNA, NM_011640; p53 protein, NP_035770). Sequence analysis showed that the lambda genomic clone containing an EcoRI fragment encompassing Trp53 (Nature 356, 215-221; 1992) that was used to prepare the targeting construct contained the Val135 codon, whereas Trp53 in laboratory mice (e.g., C57Bl6) encodes alanine at codon 135 (K. Krummel, F. Toledo, C. Lee \& G.M.W., unpublished data). The properties of the two proteins have been investigated by M.N. et al. (Oncogene, in the press).

\section{Erratum: A treasury of exceptions}

Editorial

Nat. Genet. 36, 1239 (2004).

The ENCODE project (http://www.genome.gov/ENCODE/) is funded and managed by the National Human Genome Research Institute at the US National Institutes of Health. 